GEOPHYSICAL RESEARCH LETTERS, VOL. 14, NO. 6, PAGES 595-598, JUNE 1987

\title{
LATE TERTIARY HISTORY OF HYDROTHERMAL DEPOSITION AT THE EAST PACIFIC RISE, 19ㅇ: CORRELATION TO VOLCANO-TECTONIC EVENTS
}

\author{
Mitchell Lyle \\ College of Oceanography, Oregon State University \\ Margaret Leinen \\ Graduate School of Oceanography, University of Rhode Island
}

Robert M. Owen and David K. Rea

Department of Atmospheric and Oceanic Science, University of Michigan

\begin{abstract}
Commonly it is assumed that the intensity of mid-ocean ridge hydrothermal activity should correlate with spreading rate, since high spreading rates are an indication of large subcrustal heat sources needed for intense hydrothermal activity. We have tested this hypothesis by modeling the deposition of hydrothermal precipitates from cores from Deep Sea Drilling Project Leg 92, taken on the west flank of the East Pacific Rise at $19^{\circ} \mathrm{S}$. Although spreading rates at the East Pacific Rise and its predecessor, the Mendoza Rise, have varied by only $50 \%$ in the last 30 million years, we found certain episodes, at about 25,18 , 14 , and 9 million years ago, of hydrothermal manganese deposition as much as a factor of 20 higher than equivalent Holocene accumulation. These eposides do not correlate with spreading rate changes and instead seem to occur at times of major tectonic reorganizations. We propose that ridge jumps and changes of ridge orientation may substantially increase hydrothermal activity by fracturing the ocean crust and providing seawater access to deep-seated heat sources.
\end{abstract}

\section{Introduction}

Hydrothermal cooling of basaltic crust is ubiquitous at mid-ocean ridges and may account for $20 \%$ of the total geothermal heat lost by the earth [Williams and von Herzen, 1974]. Elemental exchange between seawater and basalt during this process is instrumental in controlling the composition of seawater and how it has varied through geologic time [Berner et al, 1983; Owen and Rea, 1985]. Several attempts to model this process have made the first-order assumption that hydrothermal exchange is proportional to spreading rate [Lyle, 1976; Graham et al., 1982; Berner et al., 1983; Sleep et al., 1983]. In this paper we report the first time-series measurements of the accumulation of hydrothermal precipitates and show that the late Tertiary geologic history of hydrothermal activity is, in fact, unrelated to changes in spreading rate. Instead we observe large changes of hydrothermal activity which are more closely associated with tectonic reorganizations of the mid-ocean ridges. Presumably tectonic reorganizations profoundly affect fracture depth and spacing, resulting in increased access of seawater to hot rock, and a marked increase in the chemical exchange between basalt and seawater.

Deep Sea Drilling Project (DSDP) Site 597 (18 $48.4^{\prime}$ S, $\left.129^{\circ} 46.2^{\prime} \mathrm{W}\right)$ and Site $598\left(19^{\circ} 00.3^{\prime} \mathrm{S}, 124^{\circ} 40.6^{\prime} \mathrm{W}\right)$ were drilled during Leg 92 by the R/V Glomar Challenger in part to determine the geologic history of deposition of

\section{Copyright 1987 by the American Geophysical Union .}

Paper number $7 \mathrm{~L} 7141$.

0094-8276/87/007L-7141\$03.00 hydrothermal precipitates formed in plumes above the present East Pacific Rise and its ancestor, the Mendoza Rise (part of the old Pacific-Farallon Ridge), and wafted to the west by deep ocean currents [Leinen, Rea, et al., 1986]. Sediments at both sites are typical of central gyre sediments except for the large hydrothermally-derived component. Sedimentation

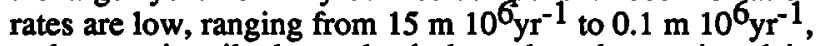
and vary primarily due to depth-dependent changes in calcite preservation. There is very little input of terrigenous or organic matter, and no evidence for diagenetic remobilization of manganese, the most redox-sensitive of the transition elements [Leinen,Rea, et al.,1986; Lyle, 1986; Lyle et al., 1986].

The hydrothermal component in Sites 597 and 598 derives from the westwart drift of hydrothermal precipitates in a plume from the East Pacific Rise axis. The plume can be traced over $1000 \mathrm{~km}$ to the west of the East Pacific Rise by anomalous ${ }^{3} \mathrm{He}$ content in deep waters [Lupton and Craig, 1981] and may be driven by geothermal heating at the East Pacific Rise [Stommel, 1982]. As the hydrothermal plume wafts away from the Rise Axis, hydrothermal precipitates settle out to sediments.

\section{Model of Hydrothermal Plume Deposition}

The mass accumulation rate of hydrothermal precipitates should decrease rapidly from the venting area, since the amount of mass in a distribution of particle sizes is preferentially in the larger, more readily sedimented particles. This is precisely what is observed at $19^{\circ} \mathrm{S}$ on the East Pacific Rise. Figure 1 shows measured accumulation rates of manganese (the major element most highly enriched in hydrothermal precipitates with respect to continental or basaltic detritus) on a profile between $18^{\circ} \mathrm{S}$ and $20^{\circ} \mathrm{S}$ and a modelled manganese accumulation rate profile [Lyle et al, 1986] assuming 1) a constant composition of hydrothermal precipitates [Dymond, 1981], 2) a log-normal particle size distribution [Lambert et al, 1981] with a median grain size of 2 micrometers, 3) Stokes settling of particles from the plume, and 4) a deep current direction normal to the rise axis. With this type of model, the distance a hydrothermal particle of diameter $\mathrm{D}$ travels is given by:

$$
\text { Dist }=\frac{\mathrm{VI}}{\mathrm{KD}^{2}}
$$

where $\mathrm{V}$ is the mean current velocity normal to the rise crest, $I$ is the injection height of hydrothermal particles, and $\mathbf{K}$ is the Stokes constant. The mass of hydrothermal deposition at some given distance from the rise crest is then calculated from the original particle distribution at the hydrothermal source area and from the mass of individual particles that would settle at this distance. By manipulating the model we can match today's sedimentary flux of 


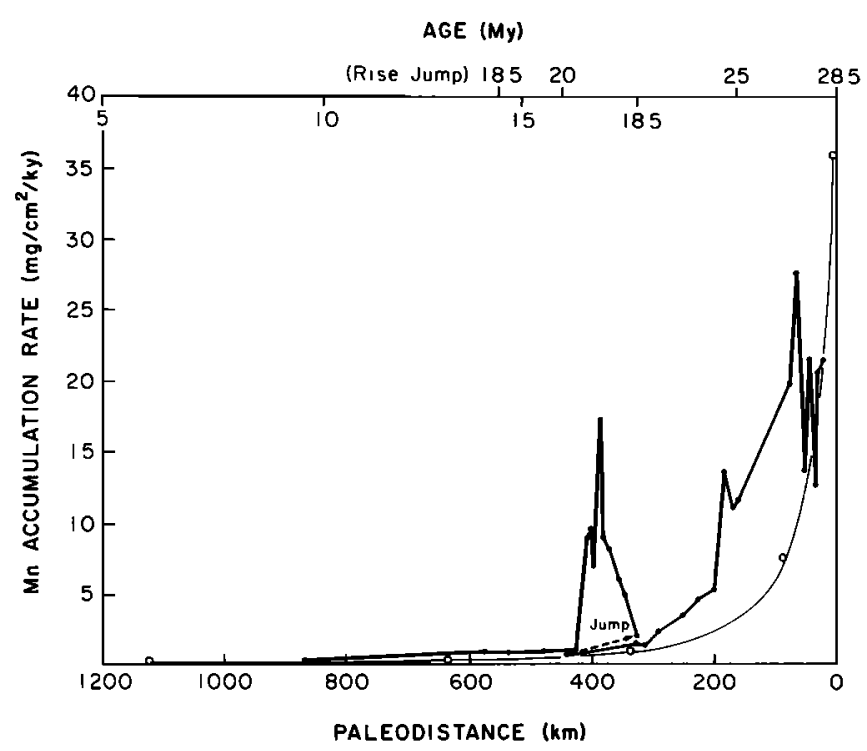

Fig.1. Observed accumulation rate of manganese at DSDP Site 597 versus distance from the East Pacific Rise Axis as compared to a modelled manganese accumulation rate assuming a ridge axis hydrothermal source for manganese. The heavy line marks the reecord from Site 597, which is broken where paleo-distances from the rise crest overlap due to the Mendoza-East Pacific Rise ridge jump at 18.5 million years ago [Mammerickx et al., 1980]. The light line marks the model accumulation rate. Open circles delineate measured manganese accumulation rates for Holocene sediments [Lyle et al., 1986]. Manganese accumulation rates were modelled by assuming a constant composition and a constant log-normal particle size distribution for hydrothermal material, and by assuming a constant current velocity normal to the ridge. See Lyle et al. [1986] for more details. Accumulation rates of manganese at Site 597 between about 27 and 24 million years ago and between 19 and 17 million years ago are sufficiently large to only have been caused by anomalously high hydrothermal activity.

hydrothermal manganese at $19^{\circ} \mathrm{S}$ with a median particle size of 2 micrometers and a mean current velocity normal to the rise axis of $1 \mathrm{~cm} \mathrm{sec}^{-1}$, typical of deep flow [Lyle et al., 1986; and Figure 1]. We have found through manipulation of the model that the manganese accumulation rate profile severely limits the range of acceptable particle size distributions and current velocities. The shape of the profile and the predicted mass flux change dramatically with changes of these parameters [Lyle et al., 1986].

Since each of the DSDP sites migrates away from the ridge axis at the spreading half-rate of the ridge, one would expect to find a similar pattern of decrease in manganese accumulation rate upcore to that found in surface sediments. High rates of manganese accumulation should be found near the base of the sediment column, when the sediments were close to the rise axis, and low rates should occur today, when both Sites 597 and 598 are more than $1000 \mathrm{~km}$ away from the East Pacific Rise. In general that is what we observe, as is illustrated by the accumulation rate profile of manganese for Site 597, shown in Figure 1. There are two intervals in this core, however, where observed accumulation rates of manganese are significantly higher than the modelled: between 24 and 27 million years ago (AN25), and between 17 and 18.5 million years ago (AN18) [Lyle et al, 1986].

These anomalies persist even when the deficiencies of the simple model we use are taken into account. The midwater current structure near the East Pacific Rise is probably the most poorly understood of the model parameters and it probably has not been constant for the past 30 million years. By a simple addition to the model, however, we can eliminate events that could have been caused by changes in current direction or velocity. We used a range of current velocities in the model, from 1 to $5 \mathrm{~cm}$ $\mathrm{sec}^{-1}$ normal to the ridge axis, and only accepted as anomalies the episodes of manganese accumulation which were higher than could be accounted for by this velocity range. An example of this is shown in Figure 2, from Site 597.

In essence, using the current velocity range also eliminates the possibility that changes in current direction could have produced these manganese accumulation rate anomalies. The best available information on mid-water flow at this latitude suggests that the present flow regime is as we have modelled it, approximately to the west and normal to the rise crest [Reid, 1982]. Minor increases of hydrothermal deposition may have occurred in the past due to a mismatch of model and the actual situation-- if the flow now is slightly off the idealized direction and flow in the past became more normal to the ridge. Major changes in current direction would reduce the hydrothermal manganese accumulation, however, since the plume would have travelled obliquely to the rise axis. Distance to the source region would thus have increased dramatically.

The sedimentation parameters in the model also help to exclude doubtful hydrothermal episodes. The assumption in the model of Stokes settling of hydrothermal plume particles neglects aggregation processes that help to increase deposition rates of fine particulate material. However, the lack of these aggregation processes in the model maximizes the deposition in the distal sediments greater than $100 \mathrm{~km}$ from the rise axis and thus also helps to exclude doubtful hydrothermal episodes.

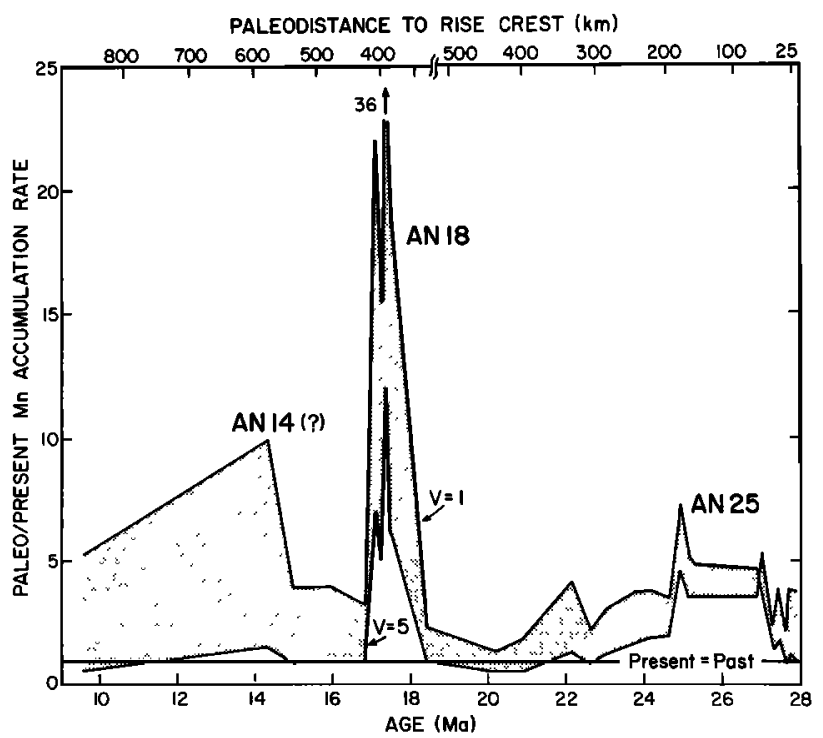

Fig. 2. Anomalous manganese accumulation rates at Site 597, arrived at by dividing the manganese accumulation rate observed in sediments of a certain age by the model Holocene rate at the equivalent distance from the rise crest (see text and Lyle et al. [1986] for details). A key variable in the model is the current velocity normal to the rise crest, $V$. Because the current velocity has probably not been constant in the past, we have chosen to use a range of current velocities between 1 and $5 \mathrm{~cm} \mathrm{sec}^{-1}$ in the model. Episodes of high hydrothermal production are delineated by time periods where the manganese accumulation rate cannot be matched using this current range. 
The lack of manganese accumulation rate anomalies younger than AN18 at Site 597 reflects the lack of age definition needed to outline events in the pelagic clays of the upper part of Site 597 and also the decreased model resolution at distances greater than $600 \mathrm{~km}$ from the rise crest. For these reasons we also analyzed material from Site $\mathbf{5 9 8}$ to examine the time period between 16 million years ago and 8 million years ago. Two more episodes of anamolous manganese accumulation rate were discovered at Site 598, between 12 and 16 million years ago (AN14) and between 8 and 11 million years ago (AN9). Both of these time periods had manganese accumulation rates about 5 times and 2 times higher respectively than the highest model rate. Manganese accumulation rate anomalies of this magnitude, observed for all 4 events, can only be explained by major increases in the production of hydrothermal manganese and not by changes in dispersion of the hydrothermal effluent [Lyle et al., 1986]. This implies that hydrothermal activity and chemical exchange between basalt and seawater at the East Pacific Rise/Mendoza Rise axis must have been significantly greater during the time periods in question.

\section{Discussion and Conclusions}

The manganese accumulation rate anomalies do not correlate either in timing or in magnitude with changes in spreading rate at the East Pacific Rise (Figure 3). The west-flank spreading half-rate at $19^{\circ} \mathrm{S}$ has varied by only about $50 \%$ between 30 million years ago and the present and has only one peak, at about 7 million years ago. During the interval for which we have accumulation rate data from Sites 597 and 598, from 28.5 million years ago to 8 million years ago, the half-spreading rate apparently changed only from

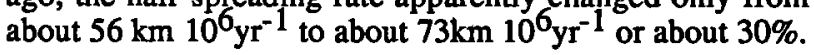
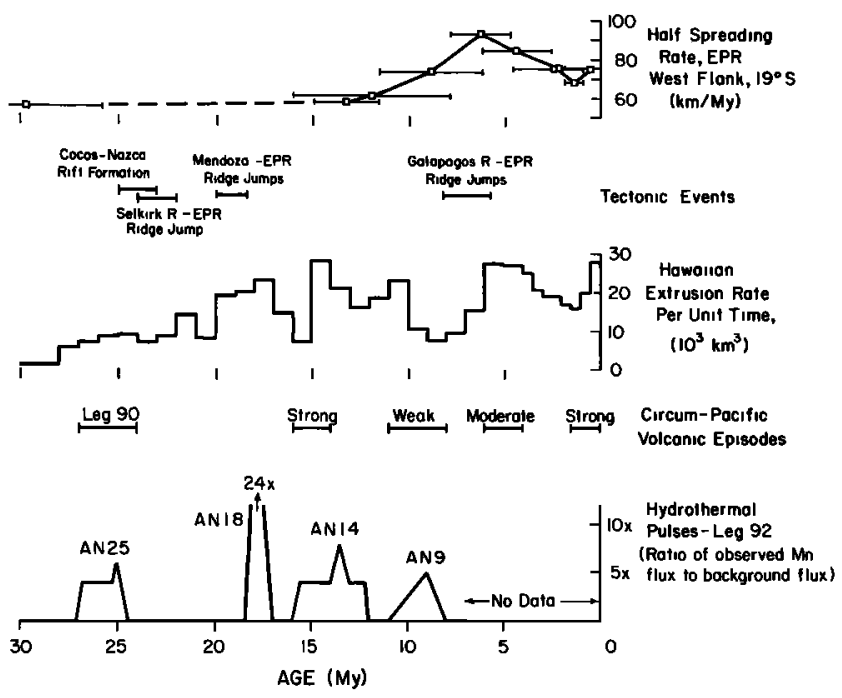

Fig. 3. Summary of volcano-tectonic events in the Pacific Basin for the last 30 million years, from Leinen, Rea, et al. [1986], Lyle et al. [1986], Hey [1977], Mammerickx et al. [1980], Kennett et al [1977],Rea and Scheidegger [1979], and Gardner et al [1985]. The half-spreading rate information is a combination of observations from Leg 92 and Rea and Scheidegger [1979]. Spreading rates have varied by less than $50 \%$ during the last 30 million years, much less than hydrothermal manganese accumulation rates have varied. The timing of hydrothermal pulses also correlates poorly with known spreading rate variations. There is better correlation between hydrothermal pulses and either circum-Pacific volcanism or known tectonic events at the East Pacific Rise.
Clearly, manganese accumulation rate anomalies we observe are an order of magnitude larger than spreading rate changes and there is no temporal correlation between hydrothermal anomalies and spreading rate changes.

There is better coincidence between the timing of hydrothermal events AN9, AN14, AN18, and AN25 and times when Pacific plates were undergoing tectonic reorganization. AN25 and AN18 match the best estimates when the Cocos-Nazca Rift was formed (25 million years ago; Hey, 1977) and when the spreading center jumped west from the Mendoza Ridge to the East Pacific Rise (18.5 million years ago; Mammerickx et al., 1980). There is no known ridge reorganization that correlates with AN14, but the tectonic history of the East Pacific Rise during this time is not well known (Mammerickx et al., 1980). AN9 may comelate with the abandonment of the fossil Galapagos Ridge (Mammerickx et al., 1980), though the match in time is not very good.

The periods of high manganese accumulation rate may also correlate in time with other indicators of Pacific -wide tectonic events, especially with episodes of circum-Pacific arc and mid-plate volcanism (Figure 3; Kennett et al., 1977; Rea and Scheidegger, 1979; Gardner et al, 1985). These episodes of arc volcanism are presumably due to changes in convergence rates and/or directions at subduction zones and should therefore be related to either changes in rate of spreading on a global scale or changes in plate geometry. In the last 20 million years there has been an important volcanic episode at 14-16 million years ago correlating with AN14, another less important episode between 11 and 8 million years ago tha correlates to AN9, and two episodes for which we have no available manganese accumulation data from our cores, between 6 and 4 million years ago, and between 1.5 million years ago and the present (Kennett et al., 1977). There may also be a regional volcanic episode at around 18 million years ago and correlating with AN18, as shown by ash layer data and by the timing of Central American volcanism (Kennett et al., 1977). Since we use manganese accumulation rate information from the present to determine anomalies in the past, there cannot be a complete coincidence between circum-Pacific volcanism and mid-ocean ridge hydrothermal activity or much of the past should accumulate manganese at a slower rate than the present.

We document that there is no correlation between sea-floor spreading rate and East Pacific Rise hydrothermal activity; rather, hydrothermal activity correlates much better with periods of ridge jumps (Owen and Rea, 1985) and to some extent also with periods of greater circum-Pacific volcanic activity. We believe that the extent of hydrothermal activity at mid-ocean ridges is dependent not only upon the total heat available, which should be proportional to the spreading rate, but also upon whether the heat is accessible to convecting seawater. The process of creating a new spreading ridge, a common occurrence in the history of the Pacific Ocean, must involve a sublithospheric heat source and subsequent cracking of an entire plate. The greatly increased number and depth of fractures and cracks brought about in this manner would explose much more basalt (by about the cube of the total fracture length) to hydrothermal alteration. Thus the first direct measurements of a hydrothermal accumulation rate time-series at the East Pacific Rise indicate that the assumption of proportionality between hydrothermal activity and spreading rate is too simplistic. However, these results do reveal an area for refinement of basalt-seawater exchange models based on the encouraging correlation observed between exchange rates and plate reorganizations.

Acknowledgments. We are grateful to the captain and the crew of the R/V Glomar Challenger as well as the rest of the Leg 92 shipboard party for the help in obtaining the cores 
and for all the discussions about hydrothermal activity. We were supported for this project by NSF grants OCE-8410146 (Lyle), OCE-841 1054 (Leinen), and OCE-8410034 (Owen).

\section{References}

Berner, R.A., A.C. Lasaga, and R.M. Garrels. The carbonate-silicate geochemical cycle and its effect on atmospheric carbon dioxide over the past 100 million years. Amer. J. Sci., 283, 641-683, 1983.

Dymond, J. Geochemistry of Nazca Plate surface sediments: an evaluation of hydrothermal, biogenic, detrital, and hydrogenous sources. in Nazca Plate: Crustal Formation and Andean Convergence, edited by L.D. Kulm, J. Dymond, E. J. Dasch, D.M. Hussong, and R. Roderick. Geol Soc Amer. Memoir 154, 133-174, 1981.

Gardner, J.V., C.S. Nelson, and P.A. Baker. Distribution and character of pale green laminae in sediment from Lord Howe Rise: a probable Late Neogene and Quaternary tephrostratigraphic record. Init. Repts. DSDP Leg 90. 1145- 1159 , U.S. Government Printing Office, Washington D.C., 1985.

Graham, D.W., M.L. Bender, D.F. Williams, and L.D. Keigwin, Jr. Strontium-calcium ratios in Cenozoic planktonic foraminifera. Geochim. Cosmochim. Acta. 46. 1281-1293, 1982.

Hey, R. Tectonic evolution of the Cocos-Nazca spreading center. Geol. Soc. Amer. Bull. 83, 1404-1420, 1977.

Kennett, J.P., A.R. McBirney, and R.C. Thunnell. Episodes of Cenozoic volcanism in the Circum-Pacific region. J. Volcan. Geotherm. Res. 2. 145-163, 1977.

Lambert, C.E., C. Jehanno, N. Silverberg, J.C. Brun-Cottan, and R. Chesselet. Log-normal distributions of suspended particles in the open ocean. J.Mar. Res. 39. 77-98, 1981.

Leinen, M.L., D.K. Rea, et al. Initial Reports of the Deep Sea Drilling Project. Leg 92,617 pp, U.S. Government Printing Office, Washington D.C., 1986.

Lupton, J.E., and H. Craig. A major helium-3 source at $15^{\circ} \mathrm{S}$ on the East Pacific Rise. Science, 214, 13-18, 1981.

Lyle, M. Estimation of hydrothermal manganese input to the oceans. Geology, 4, 733-736, 1976.
Lyle, M. Major element composition of Leg 92 sediments. Init. Repts. DSDP Leg 92. 355-370 , U.S. Government Printing Office, Washington D.C., 1986.

Lyle, M. , R.M. Owen, and M. Leinen. History of hydrothermal sedimentation at the East Pacific Rise, $19^{\circ} \mathrm{S}$. Init. Repts. DSDP Leg 92, 585-596, U.S. Government Printing Office, Washington D.C., 1986.

Mammerickx, J., E. Herron, and L. Dorman. Evidence for two fossil spreading ridges in the southeast Pacific. Geol. Soc. Amer. Bull. 91, 263-271, 1980.

Owen, R.M., and D.K. Rea. Sea-floor hydrothermal activity links climate to tectonics: the Eocene carbon dioxide greenhouse. Science, 227, 166-169, 1985.

Rea, D.K., and K.F. Scheidegger. Eastern Pacific spreading rate fluctuation and its relation to Pacific area volcanic episodes. J. Volcan. Geotherm. Res. 5. 135-148, 1979.

Reid, J.L. Evidence of an effect of heat flux from the East Pacific Rise upon the characteristics of mid-depth waters. Geophys. Res. Lett.9. 381-384, 1982.

Sleep, N.H., J.L. Morton, L.E. Burns, and T.J. Wolery. Geophysical constraints on the volume of hydrothermal flow at ridge axes. in Hydrothermal Processes at Seafloor Spreading Centers edited by P.A. Rona, K. Bostrom, L. Laubier, and K.L. Smith, Jr., Plenum Press, New York, 53-70,1983.

Stommel, $H$. Is the south Pacific helium-3 plume dynamically active? Earth Planet. Sci. Lett. 61. 63-67, 1982.

Williams, D.L., and R.P. von Herzen. Heat loss from the earth: New estimate. Geology. 2. 327-328,1974.

Margaret Leinen, Graduate School of Oceanography, University of Rhode Island, Kingston, RI 02881.

Mitchell Lyle, College of Oceanography, Oregon State University, Corvallis, OR 97331.

Robert Owen and David Rea, Department of Atmospheric and Oceanic Sciences, University of Michigan, Ann Arbor, MI 48109.

(Received 27 February 1987; accepted 13 April 1987.) 